\title{
Friction stir welding process: An investigation of microstructure and mechanical properties of Al Alloy AlMg4.5Mn joint
}

\author{
Jitender Kundu ${ }^{a^{*}}$ and Hari Singh ${ }^{b}$
}

${ }^{a}$ Research Scholar, Department of Mechanical Engineering, National Institute of Technology, Kurukshetra, 136119, India ${ }^{b}$ Professor, Department of Mechanical Engineering, National Institute of Technology, Kurukshetra, 136119, India

\begin{tabular}{l}
\hline A R T I C L EI N F O \\
\hline Article history: \\
Received 6 October, 2016 \\
Accepted 3 February 2017 \\
Available online \\
6 February 2017 \\
\hline Keywords: \\
FSW \\
AA5083 \\
Micro-hardness \\
Microstructure \\
Ductility \\
Tensile strength
\end{tabular}

\section{Introduction}

\begin{abstract}
Aluminium alloy AlMg4.5Mn has got comprehensive acceptance in the manufacturing of light weight frames, marine structures which require high strength and worthy corrosion revulsion. The present investigation work focuses on friction stir welding process in which influences of operating parameters have been studied on friction stir welded butt joints. The FSWed joints specimens have been produced by experimentation at three levels of tool traverse speed and tool rotational speed keeping input force and tool tilt angle constant. Mechanical properties and microstructure of welded joints have been investigated in the present study. Change in the microstructure at different zones which transforms the mechanical properties of welded joints was due to the asymmetrical flow of material and thermal cycles around the pin. The second phase beta grains are formed as the very high temperature reached due to input parameters combinations. Traverse speed (TS) and tool rotational speed (TRS) are taken in a range of 16$40 \mathrm{~mm} / \mathrm{min}$ and 500-1400 rpm, respectively. The best combination of parameters results in higher tensile strength which is well supported by the micro-hardness curve and the compact grains microstructure profile. Microstructure at different points and physical properties exhibited by the welded joint are well brought into line to summarize the effects of different parameters.
\end{abstract}

With the increasing competition and cost reduction scenario in the manufacturing industry, new joining techniques like friction stir welding get more attention of researchers. Friction stir welding produces sound welded joints because it minimizes the adverse effects which alter base material properties. Currently, new materials as well as composites are tested for welding through FSW. The properties of aluminium alloys as a light weight material and comparable strength over the conventional

\footnotetext{
* Corresponding author.

E-mail addresses: rsjk005@gmail.com (J. Kundu) 
materials like steel, cast iron, etc. make it more valuable for automobile and aerospace industry (Kevorkijan, 2002; Praveen \& Yarlagadda, 2005). The joining through fusion welding of aluminium alloys results in decrease of the joint strength which puts constraint on their frequent use. For obtaining high-quality joints, the aluminium alloys are being studied by various researchers (Thomas, 2012; Sidhu \& Chatha, 2012; Aliha et al., 2016, 2017; Akbari et al., 2016a,b). For the first time, friction stir welding was used by TWI in 1991 as an alternative process for the joining of aluminium alloys. This innovative welding process avoids the melting or recasting of the base plates. Moreover, the FSW welding joints produce a higher ratio of strength to weight and finer microstructure in contrast with the other joining processes for aluminium alloys (Khorrami et al., 2012; Pantelis et al., 2015; Koumoulos et al., 2011). In past few years with the transportation boom through sea ways, marine industry developed light materials with higher corrosion resistance. AA 5083 has been in demand due to its corrosive resistant and light weight qualities. For the best welding joints different efforts have been made and the influences of different working parameters have been studied. Most of the researchers reported results at the working parameters tool traverse speed (TS) more than $40 \mathrm{~mm} / \mathrm{min}$., and tool rotational speed (TRS) at very high $(2000 \mathrm{rpm})$ or at very low $(500 \mathrm{rpm})(\mathrm{Xu}$ et al., 2013; Peel et al., 2003; Patel et al., 2015; Cavaliere et al., 2008, 2009). As per author's best knowledge, for an interval of TS $16-40 \mathrm{~mm} / \mathrm{min}$ and $500-1400 \mathrm{rpm}$ of tool rotational speed, no experimental study has been done for a valuable material. The aim of the study is to find out the influence of TRS and TS on microstructure and mechanical properties.

In this solid-state welding process, two plates are clamped along a common weld line on a special design fixture and a rotating tool shoulder with a pin is inserted downward at the weld line of two plates until it touches the top surface of the plates (see Fig. 1). After generating enough frictional heat it starts to move in transverse direction on the pre-defined weld line. Different research investigations have been carried out for efficient joining to make it valuable over other joining processes (Gibson et al., 2014; Shultz et al., 2013; Yuan et al., 2012; Patel et al., 2015; Kundu \& Singh, 2016). Joint properties for different conditions like corrosion are studied which have myriad of benefits.

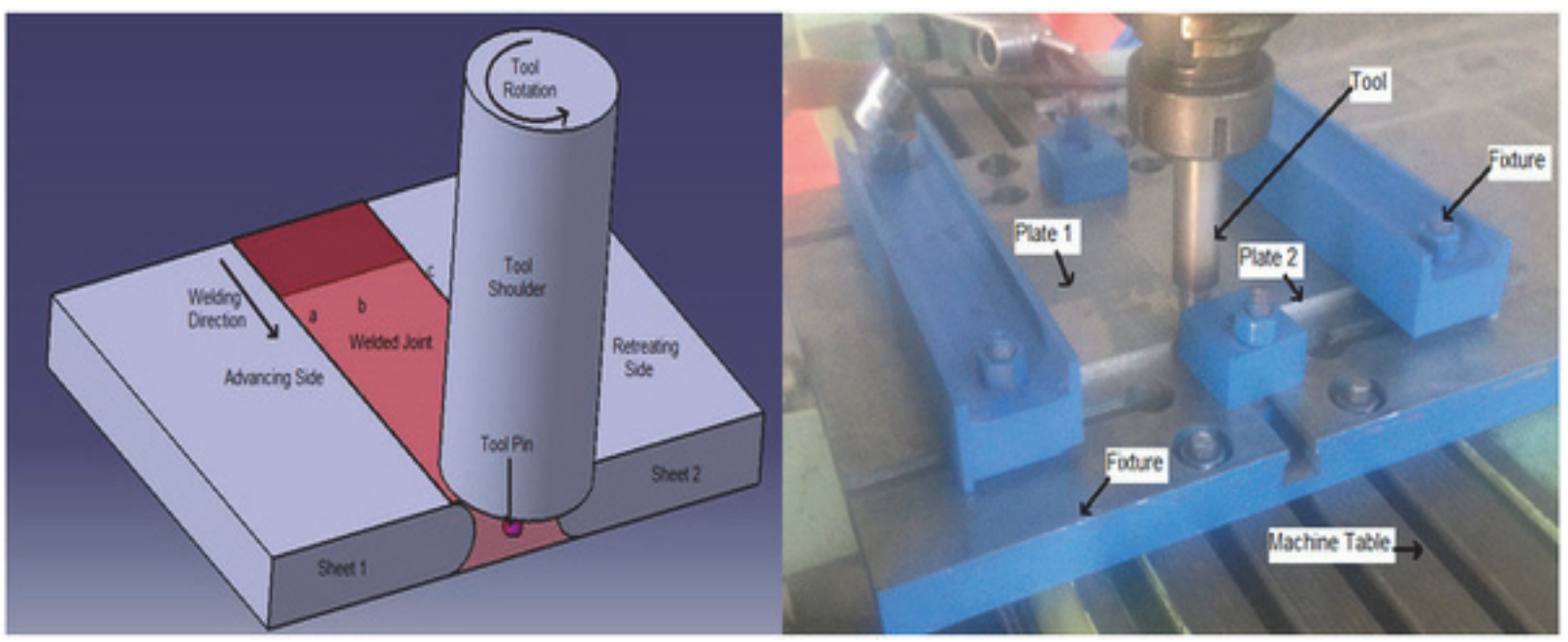

Fig. 1. Mechanism of FSW Process

In current research study aluminium alloy 5083-H321 (AlMg4.5Mn) has been selected due to its wide applications in aerospace, manufacturing and marine industry. Recently this aluminium alloy grade has also been used for manufacturing of smartphone body due to its high strength and light weight characteristics vital for the smartphone manufacturers (Heinz et al., 2000; Burford et al., 2010; Baffari et al., 2014). An attempt has thus been made to study the effects of tool rotational speed and traverse speed on the mechanical properties. Morphology analysis of the welded joints has been done for supporting the significance of the results. 


\section{Materials and Methods}

The base material AA5083 cold rolled H-321, tempered and cut into plates with dimensions of $150 \times 75 \times 4.5 \mathrm{~mm}^{3}$ has been used for friction stir welding process. Before welding process, edges of the base material plates are prepared and it is made sure that these are free from built-in edges and misalignment along the weld line. The chemical composition of the parent material has been tested at Spectro Analytical Labs New Delhi, results have been reported in Table 1. Nine experiments have been conducted with the various symmetric combination of TRS and TS on a modified vertical milling machine. Other input process parameters have been fixed at economical levels based upon review of literature (Vijay and Murugan 2010, Kuram and Ozcelik 2013, Deepandurai and Parameshwaran 2015, Kundu and Singh 2016). Input tool tilt angle has been fixed as $2^{\circ}$ and the initial force has been kept 6 $\mathrm{KN}$. Initial tool plunge time and waiting time has been taken $70(60+10)$ seconds. Experimental details are given in Table 2 .

Table 1. Chemical Composition of AA5083-H321

\begin{tabular}{llllllll}
\hline $\mathbf{M g}$ & $\mathbf{M n}$ & $\mathbf{F e}$ & $\mathbf{S i}$ & $\mathbf{C r}$ & $\mathbf{Z n}$ & $\mathbf{V}$ & Al \\
\hline 4.3 & 0.63 & 0.13 & 0.076 & 0.06 & 0.03 & 0.01 & Balance \\
\hline
\end{tabular}

Table 2. Experimental details

\begin{tabular}{cccc}
\hline Run & Sample No. & $\begin{array}{c}\text { Traverse Speed } \\
(\mathrm{mm} / \mathrm{min})\end{array}$ & $\begin{array}{c}\text { Tool Rotational Speed } \\
(\mathrm{rpm})\end{array}$ \\
\hline 1 & S1 & 16 & 500 \\
2 & S2 & 28 & 500 \\
3 & S3 & 40 & 500 \\
4 & S4 & 16 & 950 \\
5 & S5 & 28 & 950 \\
6 & S6 & 40 & 950 \\
7 & S7 & 16 & 1400 \\
8 & S & 28 & 1400 \\
9 & S9 & 40 & 1400 \\
\hline
\end{tabular}

For the experimentation, tool steel-H13 has been manufactured having tool shoulder diameter and tool pin diameter $20 \mathrm{~mm}$ and $6 \mathrm{~mm}$, respectively with the shoulder face concave angle $6^{\circ}$ as (Raju and Kumar 2014) shown in Fig. 2.

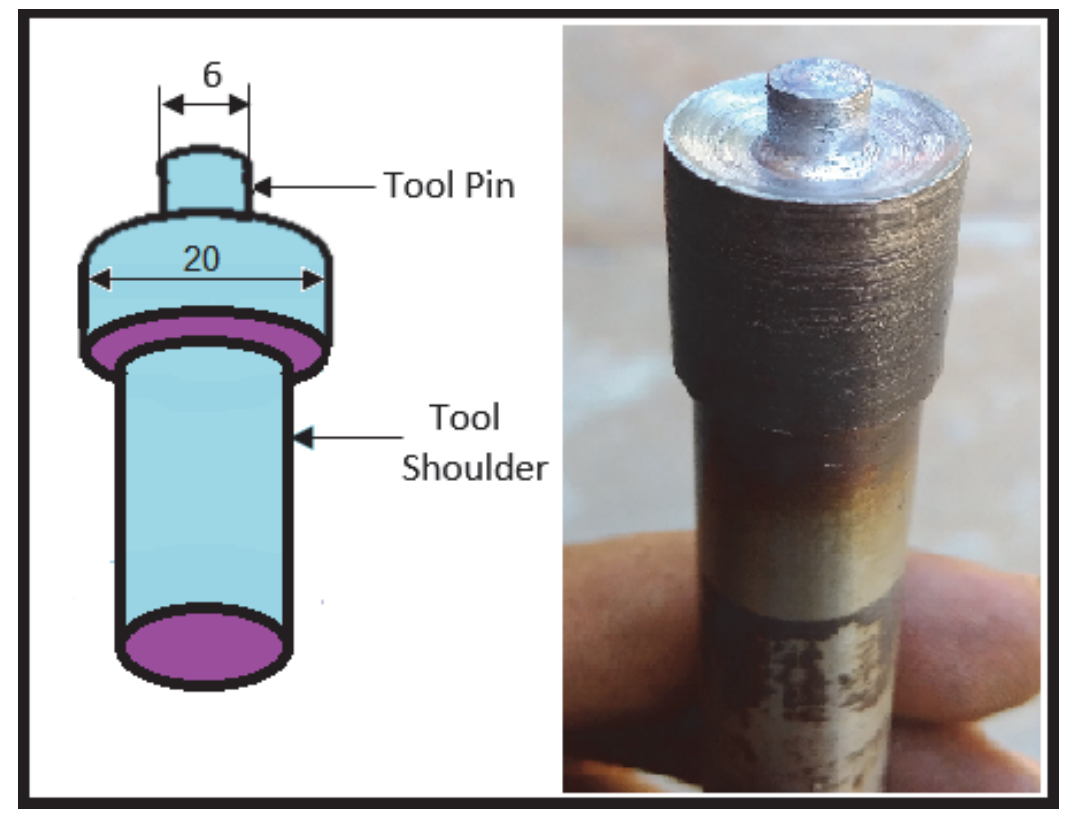

Fig. 2. Tool used for friction stir welding 
A concave shaped shoulder and the cylindrical pin with flat face have been used for the welding process. In the welding process, weld line direction is perpendicular to the rolling direction of base material plates.

Welded joints have been inspected through visual as well as mechanical testing e.g. tensile strength and micro-hardness. Tensile test specimens have been cut according to ASTM-E8 along the transverse direction. A Vickers micro-hardness testing has been done with a dwell time $10 \mathrm{sec}$ and load $1 \mathrm{kN}$. Mechanical testing of all the welded joints was done at Govt. Testing Lab CITCO Chandigarh, India. Microstructure and grain formation examination of the three different zones has been done on scanning electron microscope equipped with digital image processing unit available at Physics Department, National Institute of Technology Kurukshetra, India.

\section{Results and discussion}

\subsection{Microstructure}

Friction stir welding of AA5083 generates three different zones named as weld Nugget Zone (NZ), Thermo-mechanically Affected Zone (TMAZ), Heat Affected Zone (HAZ), which have been shown in Fig. 3. Central zone NZ has maximum temperature due to higher strain rate under the tool shoulder.
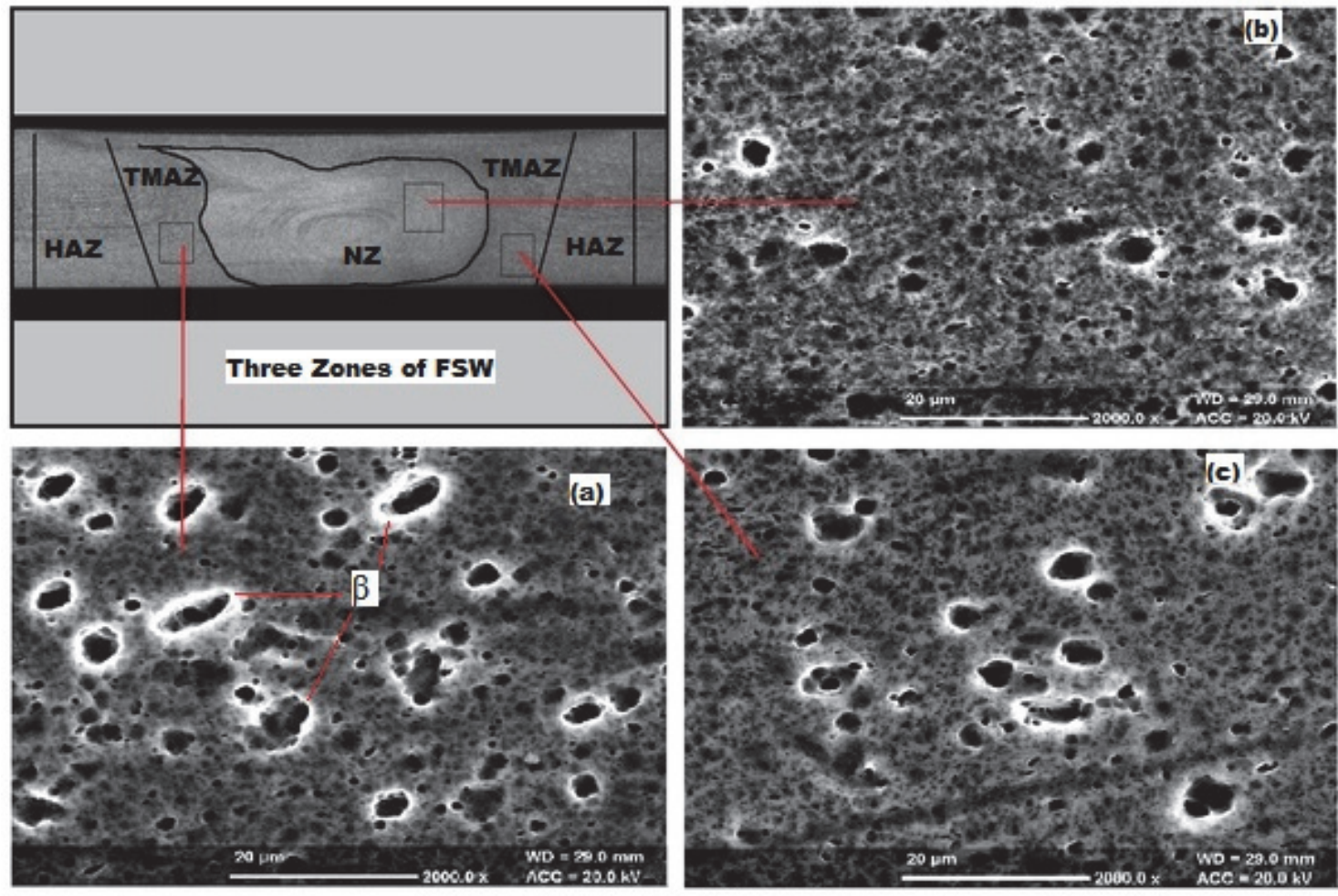

Fig. 3. (a) Three zones of FSW joint, (b) SEM image of NZ, (c) \& (d) SEM images of TMAZ

The temperature of the material almost reached $500^{\circ} \mathrm{C}(\mathrm{Xu}$ et al., 2013). This zone is also called recrystallized zone due to recrystallization of the grains and its shape almost coinciding with that of the tool. Grains in NZ have been found fine and equal in size approximately. From top surface to bottom surface, grain size is also decreased due to peak temperature difference between top to bottom surface thickness; many researchers have proposed that the fine grain size in NZ area is due to the rotation of the sub-grains which produce dynamic recrystallization in friction stir welding (Yang et al., 2014; Xu et al., 2012; Liu et al., 2010). On the top of the surface, centrifugal force remains very high which in effect produces high compression force per unit area resulting in a small number of crystal nuclei and higher grain size. It has been suggested by authors that the dislocations between the grains are occupied by sub-grains particles which prevent the growth and size of second phase particles (Peel et al., 2003; 
Yuan et al., 2012; Song et al. 2012). The onion shape ring formation in the structure is due to the deformation and different thermal cycles (see Fig. 4).

In friction stir welding, TMAZ (a transition zone) has been generated on both sides of the NZ, which is the effect of heat generated and deformation produced by tool shoulder and pin in the solid state welding. The grains produced due to deformation and heat generated in TMAZ are more elongated and distinct from NZ grains. The grain structure of the TMAZ for advancing side and retreating side are shown in Fig. 5. The difference between the grain structures of two sides is due to the difference in the plastic flow state of the material on both sides (Xu et al. 2013). The flow of the material from AS to RS is less sophisticated than the plastic flow of the material from RS to AS. At RS, the plastic flow state material transition is very easy and diffusion of the boundary in RS is more. After the TMAZ, there is a narrow heat affected zone (HAZ).
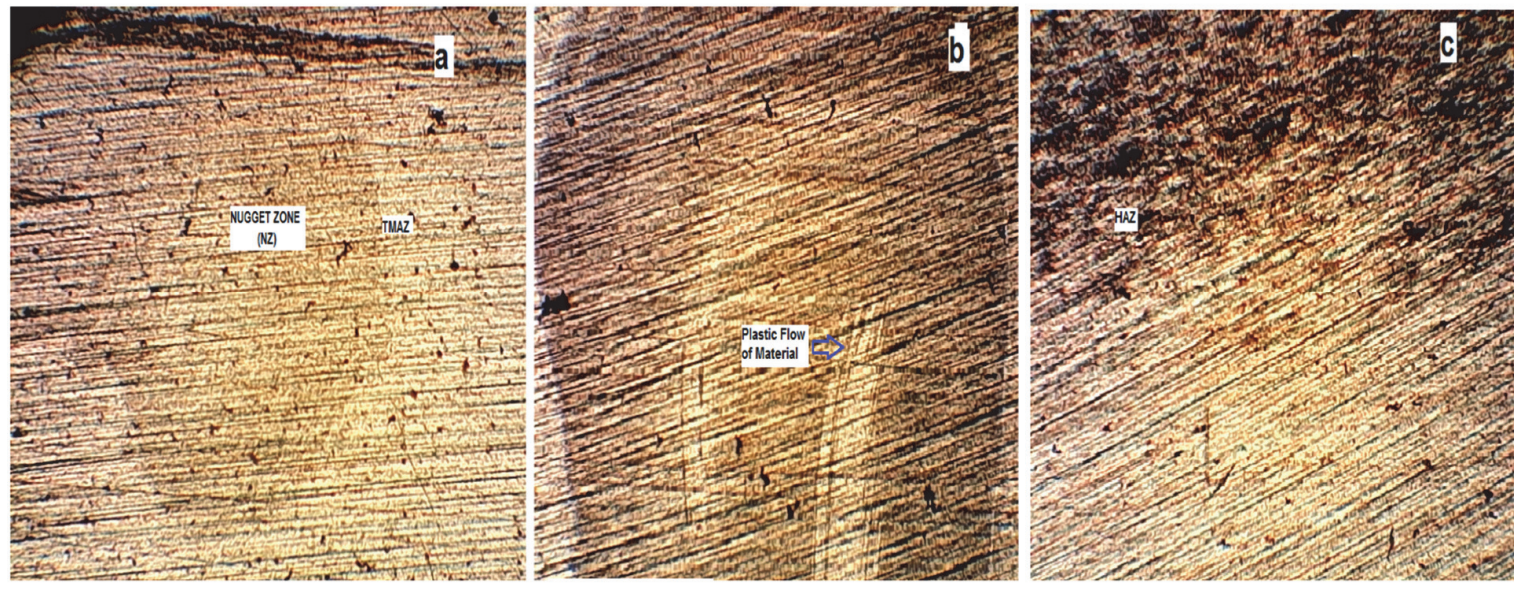

Fig. 4. Optical micrographs of (a) Central NZ, (b) Plastic flow of material and intermixing of base material, (c) Heat affected zone
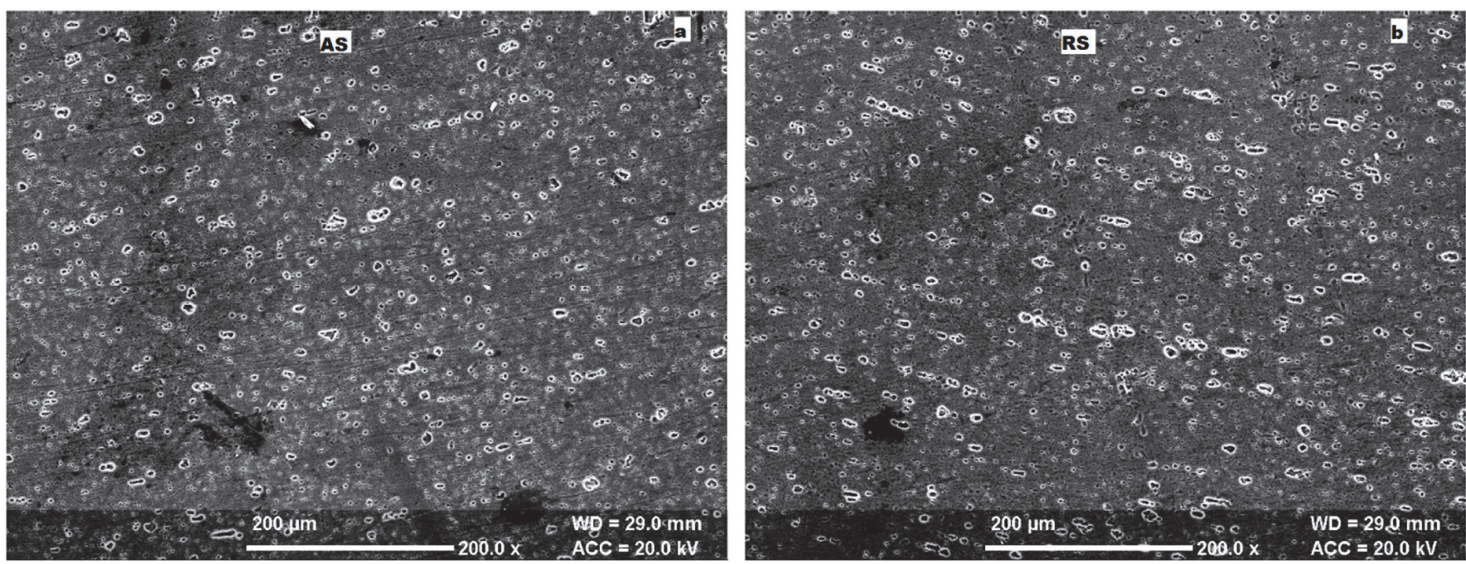

Fig. 5. SEM micrographs (a) microstructure of AS, (b) microstructure of RS

In the conventional welding process i.e. Gas Metal Arc Welding of aluminium and its alloy, the HAZ is the weakest zone formed due to the change in strength of aluminium with varying temperature range. In such processes, HAZ is wide having fragile bonding strength. But in FSW process, there is no melting of aluminium alloy and thus very small chance for HAZ to be widened and this results in improved welded joint strength. The maximum temperature range for the $\mathrm{HAZ}$ is up to $400^{\circ} \mathrm{C}$ for friction stir welding of aluminium alloy (Xu et al., 2009; Colegrove et al., 2013). From scanning electron micrographs of grains, it is revealed that the second phase particles are distributed at lower tool rotational speed of $500 \mathrm{rpm}$ and the higher traverse speed of the tool shoulder with respect to workpiece. Abnormal growth of the second phase particles on the surface is distributed equally as seen 
in figure 3(b), 3(c) and 3(d). The Higher density of the second phase particles defends the maximum movement of the dislocations and the finer grain formation in NZ.

\subsection{Micro-hardness}

In Al-Mg alloy-5083, high strength is attributed to the dense solute concentration and strain hardening phenomenon (Peel et al., 2003; Steuwer et al., 2006). The hardness of the welded joint is jointly affected due to strain rate modulation and high-temperature variation which transform the microstructure at different zones. For the good distributions of micro-hardness eleven point values are taken for a single sample in the transverse direction of the welded joint. Five points have been taken each side of the centre of the weld joint with a distance of $2.5 \mathrm{~mm}$ from each other. Micro-hardness range for base material AA5083 is 90-95 HV. Fig. 6 reveals that the welded joint has a lower hardness as compared with the base material hardness. Rao et al. (2013) observed the same trend for the aluminium alloy 5083. The lower value of the hardness is exhibited by softening region, which is shown by all the welded joints at different traverse speed and tool rotational speed. For the sample no. 1, there is a sharp decrease in hardness from AS of the base material (BM) HAZ to NZ and after NZ to RS. The second welding joint sample relatively shows higher hardness at NZ as compared to TMAZ and HAZ in both AS and RS.

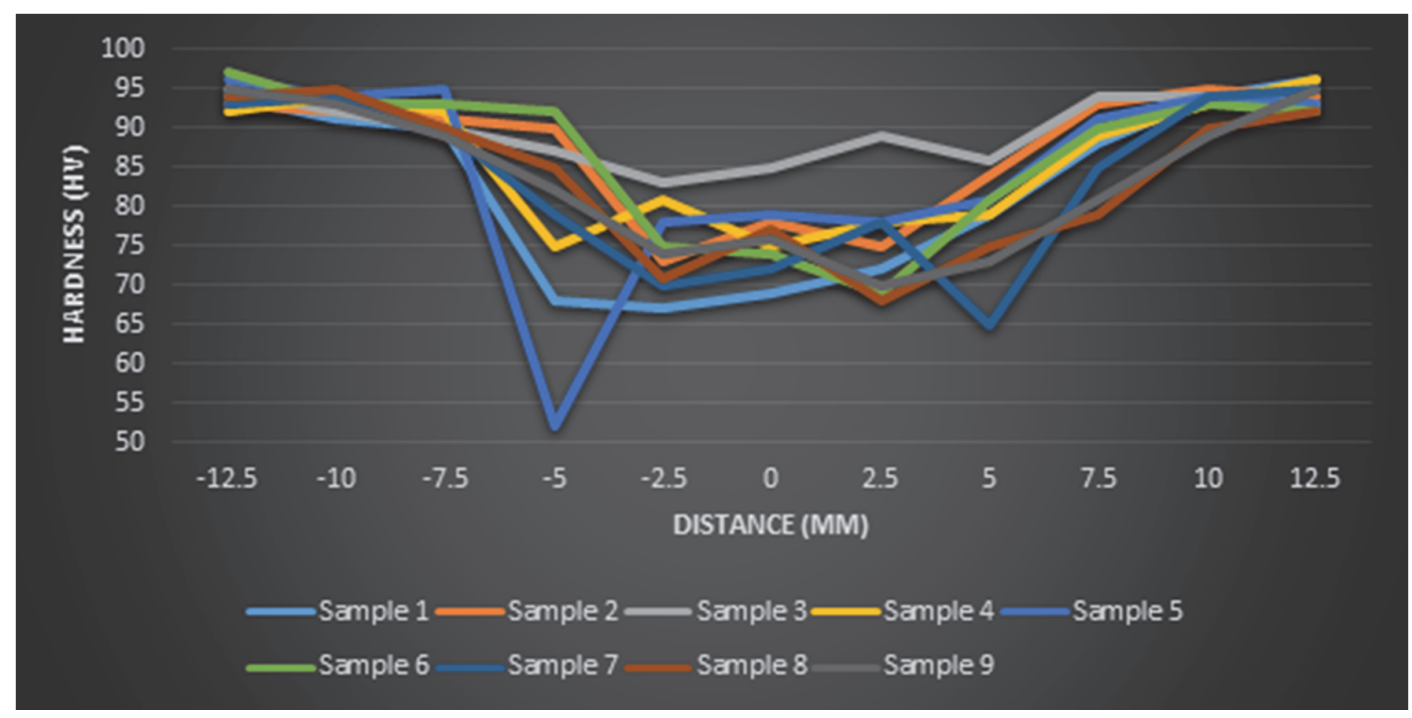

Fig. 6. Vickers micro-hardness of all samples

The hardness of sample no. 5 has a good matching with the microstructure and it shows approximately $20 \%$ difference between hardness at NZ and TMAZ or HAZ. NZ has pinned second phase particles within the dislocations of the crystal, which form higher compact grain structure resulting in higher micro-hardness.

Sample no. 3 shows a minimum change in the hardness of TMAZ and HAZ with the NZ. Overall higher Vickers micro-hardness of NZ is 67-89 HV. For TMAZ or HAZ, the Vickers micro-hardness range has been wide as 52-94 $\mathrm{HV}$. The change of process parameters affects the temperature distribution profile and plastic flow of material under the tool shoulder which spread hardness in long range. Vickers micro-hardness for all the samples has been found a slightly low from the BM AA5083. Fig. 7 shows the hardness trends for all the samples.

\subsection{Tensile Strength}

For any welding joint, tensile strength test is a threshold barrier to check the usefulness of the welded joint. The reported results are the average of three sample tests for the joint tensile strength test. The average values of tensile strength are given in Fig. 8 for all samples. The values are varying according to the combined effects of input process variables. Tensile strength at a traverse speed of 16 $\mathrm{mm} / \mathrm{min}$ has been noted minimum for all values of tool rotational speed. Low traverse speed produced 
higher temperature gradient. This higher temperature gradient produced a better chance for combining second phase particles which transformed in large size crystal imperfections resulting in lower tensile strength. The tensile strength range for the first level of traverse speed is $220-281 \mathrm{MPa}$.

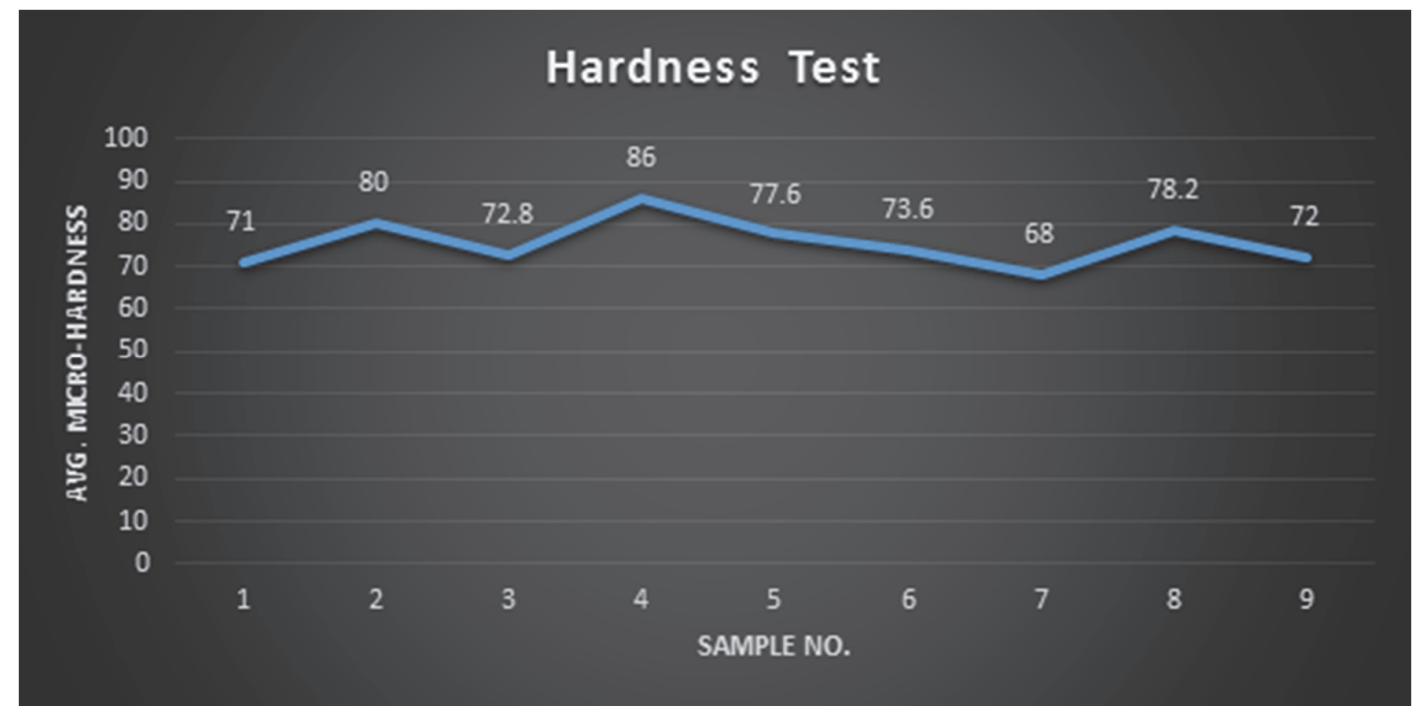

Fig. 7. Vickers micro-hardness values for all nine samples

At the second level of traverse speed i.e. $28 \mathrm{~mm} / \mathrm{min}$ thermal cycles per $(\mathrm{mm})$ were comparatively low; the second phase particles are pinned in dislocations and better symmetric grain structure leads to better strength.

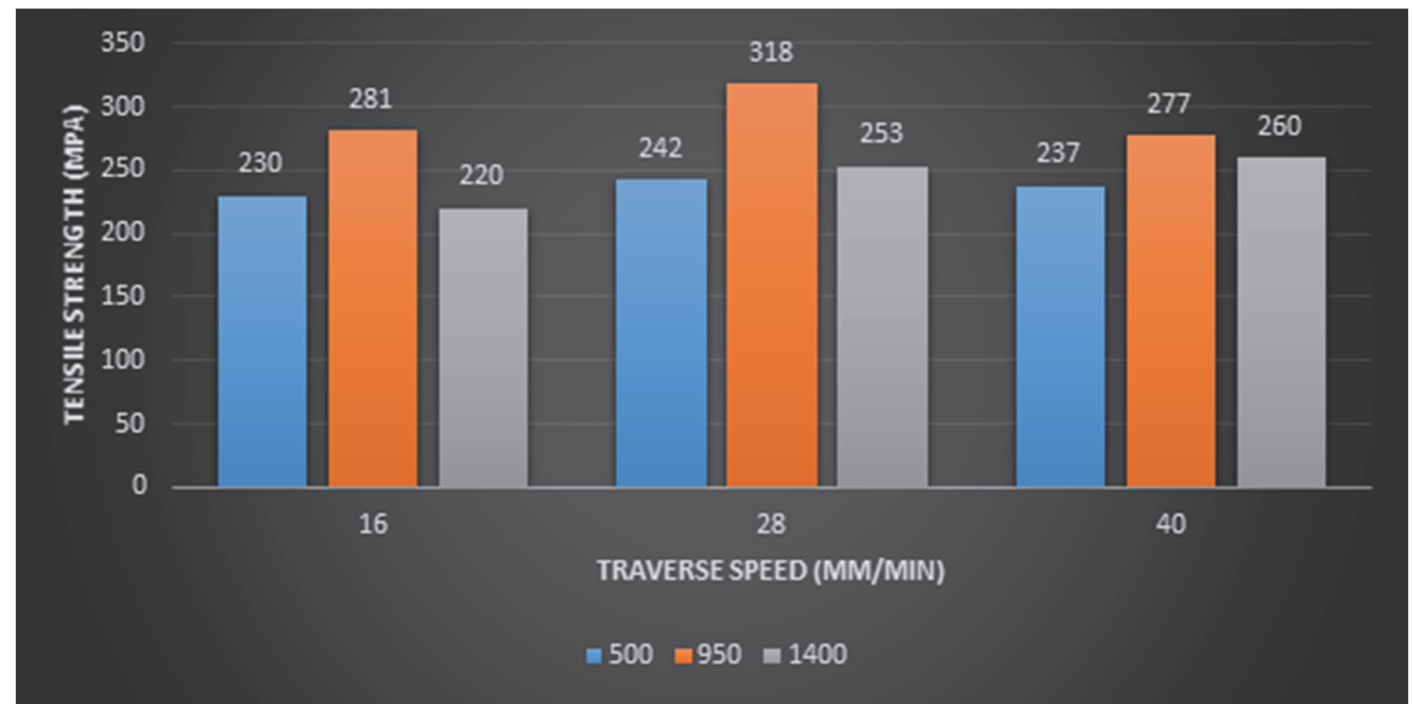

Fig. 8. Tensile strength at variation of TS and TRS

As traverse speed is increased to $40 \mathrm{~mm} / \mathrm{min}$, friction heat between tool shoulder and pin with base material is recorded low; this results in an unsymmetrical plastic flow of material under the tool decreasing the intermixing of recrystallized grains. This poor intermixing of material reduces the tensile strength. Trend in tensile strength with the variation of TRS is shown in Figs. 9 and 10. At lower TRS i.e. $500 \mathrm{rpm}$, tensile strength varies from 230 to $242 \mathrm{MPa}$. The best welded joint strength of $318 \mathrm{MPa}$ was produced at $950 \mathrm{rpm}$ of TRS. Welded joint strength for all the nine samples has been shown in Fig. 9. 


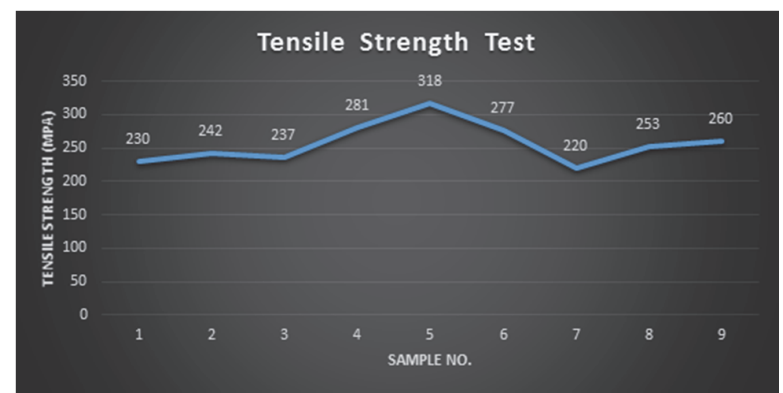

Fig. 9.Tensile strength vs. sample number

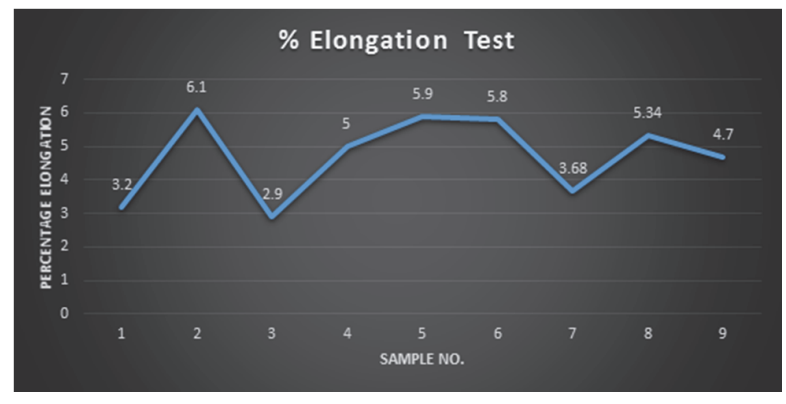

Fig. 10. Percentage Elongation vs. Sample number

Ductility of the welded joint of sample number 5 is increased due to finer grain size and smaller second phase particles. The percentage elongation varies from 2.9 to 6.1 as shown in Fig. 10. In sample no. 3 , the ductility of the butt welded joint decreases to $2.9 \%$ due to the presence of large size of second phase particles.

\section{Conclusions}

An investigation of friction stir welding of AA5083-H321 using different levels of input process parameters i.e. traverse speed and tool rotational speed, has been conducted. The morphology analysis and mechanical properties of all the butt welded joints have been investigated. From the experimental work and joint analysis, the following conclusions are drawn:

1) The optical micrographs and SEM revealed that different zones have different microstructure grain profiles. NZ has very fine grains due to better plastic flow but HAZ has coarse grains resulting in decreased welded joint strength.

2) Vickers micro-hardness reveals that NZ has a higher hardness average value of $75 \mathrm{HV}$. But hardness is lower in the range of 68-73 HV for the TMAZ and HAZ. Microstructure profiles of these welding zones reveal the difference of hardness values.

3) Butt joint welding strength for the fifth sample is $318 \mathrm{MPa}$ which is the highest among all the samples and this corresponds to $28 \mathrm{~mm} / \mathrm{min}$ and $950 \mathrm{rpm}$ of TS and TRS, respectively. It is also revealed that traverse speed has a higher impact than tool rotational speed on the tensile strength of the butt welded joint.

4) Ductility of the welded joint of the second and the fifth sample has been observed $6.1 \%$ and 5.9 $\%$, respectively. It is also revealed that these welding joints have higher tensile strength and finer microstructure.

\section{Acknowledgement}

The authors would like to acknowledge National Institute of Technology, Kurukshetra, India for providing requisite facilities to accomplish this work.

\section{References}

Akbari, M., Khalkhali, A., Keshavarz, S. M. E., \& Sarikhani, E. (2016a). The effect of in-process cooling conditions on temperature, force, wear resistance, microstructural, and mechanical properties of friction stir processed A356. Proceedings of the Institution of Mechanical Engineers, Part L: Journal of Materials Design and Applications, 1464420716630569.

Akbari, M., Aliha, M. R. M., Keshavarz, S. M. E., \& Bonyadi, A. (2016b). Effect of tool parameters on mechanical properties, temperature, and force generation during FSW. Proceedings of the Institution of Mechanical Engineers, Part L: Journal of Materials: Design and Applications, 1464420716681591. 
Aliha, M. R. M., Shahheidari, M., Bisadi, M., Akbari, M., \& Hossain, S. (2016). Mechanical and metallurgical properties of dissimilar AA6061-T6 and AA7277-T6 joint made by FSW technique. The International Journal of Advanced Manufacturing Technology, 86(9-12), 2551-2565.

Aliha, M. R M., Fotouhi, Y., \& Berto, F. (2017). Experimental notched fracture resistance study for the interface of $\mathrm{Al}-\mathrm{Cu}$ bimetal joints welded by friction stir welding. Proceedings of the Institution of Mechanical Engineers, Part B: Journal of Engineering Manufacture, 0954405416688935.

Baffari, D., Buffa, G., Campanella, D., Fratini, L., \& Micari, F. (2014). Friction based solid state welding techniques for transportation industry applications. Procedia CIRP, 18, 162-167.

Burford, D., Britos, P. G., Boldsaikhan, E., \& Brown, J. (2010, May). Evaluation of friction stir weld process and properties for aerospace application: e-NDE for friction stir processes. In 6th annual technical review meeting, FAA Joint Advanced Materials \& Structures (JAMS).

Cavaliere, P., De Santis, A., Panella, F., \& Squillace, A. (2009). Effect of welding parameters on mechanical and microstructural properties of dissimilar AA6082-AA2024 joints produced by friction stir welding. Materials \& Design, 30(3), 609-616.

Cavaliere, P., Squillace, A., \& Panella, F. (2008). Effect of welding parameters on mechanical and microstructural properties of AA6082 joints produced by friction stir welding. Journal of Materials Processing Technology, 200(1), 364-372.

Colegrove, P. A., Shercliff, H. R., \& Zettler, R. (2007). Model for predicting heat generation and temperature in friction stir welding from the material properties. Science and Technology of Welding and Joining, 12(4), 284-297.

Deepandurai, K., \& Parameshwaran, R. (2016). Multiresponse Optimization of FSW Parameters for Cast AA7075/SiCp Composite. Materials and Manufacturing Processes, 31(10), 1333-1341.

Gibson, B. T., Lammlein, D. H., Prater, T. J., Longhurst, W. R., Cox, C. D., Ballun, M. C., ... \& Strauss, A. M. (2014). Friction stir welding: process, automation, and control. Journal of Manufacturing Processes, 16(1), 56-73.

Koumoulos, E. P., Charitidis, C. A., Daniolos, N. M., \& Pantelis, D. I. (2011). Nanomechanical properties of friction stir welded AA6082-T6 aluminum alloy. Materials Science and Engineering: $B, 176(19), 1585-1589$.

Khorrami, M. S., Kazeminezhad, M., \& Kokabi, A. H. (2012). Microstructure evolutions after friction stir welding of severely deformed aluminum sheets. Materials \& Design, 40, 364-372.

Kundu, J., \& Singh, H. (2016). Friction stir welding of dissimilar Al alloys: effect of process parameters on mechanical properties. Engineering Solid Mechanics, 4(3), 125-132.

Kuram, E., \& Ozcelik, B. (2013). Multi-objective optimization using Taguchi based grey relational analysis for micro-milling of Al 7075 material with ball nose end mill. Measurement, 46(6), 18491864.

Liu, H. J., Zhou, L., \& Liu, Q. W. (2010). Microstructural characteristics and mechanical properties of friction stir welded joints of Ti-6Al-4V titanium alloy. Materials \& Design, 31(3), 1650-1655.

Heinz, A., Haszler, A., Keidel, C., Moldenhauer, S., Benedictus, R., \& Miller, W. S. (2000). Recent development in aluminium alloys for aerospace applications. Materials Science and Engineering: A, 280(1), 102-107.

Pantelis, D. I., Karakizis, P. N., Daniolos, N. M., Charitidis, C. A., Koumoulos, E. P., \& Dragatogiannis, D. A. (2016). Microstructural study and mechanical properties of dissimilar friction stir welded AA5083-H111 and AA6082-T6 reinforced with SiC nanoparticles. Materials and Manufacturing Processes, 31(3), 264-274.

Patel, V. V., Badheka, V., \& Kumar, A. (2016). Influence of friction stir processed parameters on superplasticity of Al-Zn-Mg-Cu alloy. Materials and Manufacturing Processes, 31(12), 1573-1582.

Peel, M., Steuwer, A., Preuss, M., \& Withers, P. J. (2003). Microstructure, mechanical properties and residual stresses as a function of welding speed in aluminium AA5083 friction stir welds. Acta Materialia, 51(16), 4791-4801.

Praveen, P., \& Yarlagadda, P. K. D. V. (2005). Meeting challenges in welding of aluminum alloys through pulse gas metal arc welding. Journal of Materials Processing Technology, 164, 1106-1112.

Rao, D., Huber, K., Heerens, J., Dos Santos, J. F., \& Huber, N. (2013). Asymmetric mechanical properties and tensile behaviour prediction of aluminium alloy 5083 friction stir welding joints. Materials Science and Engineering: A, 565, 44-50. 
Raju, L. S., \& Kumar, A. (2014). Influence of Al 2 O 3 particles on the microstructure and mechanical properties of copper surface composites fabricated by friction stir processing. Defence Technology, 10(4), 375-383.

Sidhu, M. S., \& Chatha, S. S. (2012). Friction stir welding-process and its variables: a review. International Journal of Emerging Technology and Advanced Engineering, 2(12), 275-279.

Shojaeefard, M. H., Behnagh, R. A., Akbari, M., Givi, M. K. B., \& Farhani, F. (2013). Modelling and Pareto optimization of mechanical properties of friction stir welded AA7075/AA5083 butt joints using neural network and particle swarm algorithm. Materials \& Design, 44, 190-198.

Song, K. H., Kim, W. Y., \& Nakata, K. (2012). Evaluation of microstructures and mechanical properties of friction stir welded lap joints of Inconel 600/SS 400. Materials \& Design, 35, 126-132.

Steuwer, A., Peel, M. J., \& Withers, P. J. (2006). Dissimilar friction stir welds in AA5083-AA6082: the effect of process parameters on residual stress. Materials Science and Engineering: A, 441(1), 187-196.

Shultz, E. F., Fehrenbacher, A., Pfefferkorn, F. E., Zinn, M. R., \& Ferrier, N. J. (2013). Shared control of robotic friction stir welding in the presence of imperfect joint fit-up. Journal of Manufacturing Processes, 15(1), 25-33.

Verma, S., \& Misra, J. (2015). A Critical Review of Friction Stir Welding Process. DAAAM International Scientific Book, 249-266.

Vijay, S. J., \& Murugan, N. (2010). Influence of tool pin profile on the metallurgical and mechanical properties of friction stir welded Al-10wt.\% TiB 2 metal matrix composite. Materials \& Design, $31(7), 3585-3589$.

Kevorkijan, V. (2002). Economic benefits of the substitution of traditional cast iron and steel by aluminum and magnesium based materials in automotive segment. Metalurgija, 8(3), 251-258.

Xu, W., Liu, J., Luan, G., \& Dong, C. (2009). Temperature evolution, microstructure and mechanical properties of friction stir welded thick 2219-O aluminum alloy joints. Materials \& Design, 30(6), 1886-1893.

Xu, W. F., Liu, J. H., Chen, D. L., Luan, G. H., \& Yao, J. S. (2012). Improvements of strength and ductility in aluminum alloy joints via rapid cooling during friction stir welding. Materials Science and Engineering: A, 548, 89-98.

$\mathrm{Xu}, \mathrm{W} ., \mathrm{Liu}, \mathrm{J} ., \mathrm{Zhu}, \mathrm{H} .$, \& Fu, L. (2013). Influence of welding parameters and tool pin profile on microstructure and mechanical properties along the thickness in a friction stir welded aluminum alloy. Materials \& Design, 47, 599-606.

Yang, S., Zhang, D., Tuo, W., \& Yu, Z. (2014). Microstructures and properties of extruded Al-0.6 Mg0.6 Si aluminium alloy for high-speed vehicle. Procedia Engineering, 81, 598-603.

Yuan, W., Mishra, R. S., Carlson, B., Verma, R., \& Mishra, R. K. (2012). Material flow and microstructural evolution during friction stir spot welding of AZ31 magnesium alloy. Materials Science and Engineering: A, 543, 200-209.

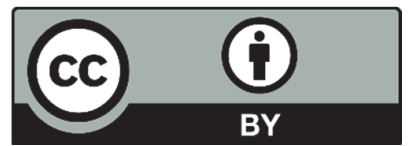

(C) 2017 by the authors; licensee Growing Science, Canada. This is an open access article distributed under the terms and conditions of the Creative Commons Attribution (CC-BY) license (http://creativecommons.org/licenses/by/4.0/). 